\title{
Anti-Markovnikov Hydroamination of Alkenes Catalyzed by a Two-Component Organic Photoredox System: Direct Access to Phenethylamine Derivatives
}

\author{
Tien M. Nguyen, Namita Manohar, and Prof. David A. Nicewicz \\ Department of Chemistry, University of North Carolina at Chapel Hill, Chapel Hill, NC 27599-3290 \\ (USA)
}

\section{Keywords}

photoredox; organocatalysis; radicals; amines; alkenes

\begin{abstract}
Carbon-nitrogen bonds are ubiquitous in biologically active compounds and appear as numerous but distinct structural motifs.[1] A particularly prevalent class of nitrogencontaining bioactive compounds, phenethylamine derivatives, display wide-ranging medicinal properties from anti-depressants to fungicides (Figure 1). One of the most direct means of accessing amine derivatives is the hydroamination reaction of alkenes.[2] The synthetic community has developed numerous methods for the hydroamination of olefins catalyzed by late transition metals that generally proceed with Markovnikov selectivity. In contrast, anti-Markovnikov-selective methods are less prevalent and often require either a large excess of alkene, strong bases or precious transition metal catalysts.[3-6] In addition, hydroboration-amination strategies provide access to formal anti-Markovnikov hydroamination products but are indirect.[7]
\end{abstract}

Our lab recently demonstrated the intramolecular anti-Markovnikov hydroamination of unsaturated amines employing the Fukuzumi acridinium photoredox catalyst and thiophenol as a hydrogen atom donor (eq 1).[8a] We hoped to expand the general utility of this catalyst system to include intermolecular examples with the goal of accessing biologically-relevant amines. Herein, we report the use of a mild two-component organic photoredox catalyst system that enables a direct anti-Markovnikov hydroamination of alkenes to access the important phenethylamine motif and also allows the use of nitrogen heteroaromatic nucleophiles (eq 2).

Beginning with our previously reported conditions, we tested the intermolecular reaction between $\beta$-methylstyrene and amine nucleophiles (Table 1). Employing trifluoromethanesulfonamide $\left(\mathrm{TfNH}_{2}\right)$ as the nucleophile and thiophenol as the co-catalyst, we obtained a single regioisomer of $N$-triflylamphetamine in $87 \%$ yield (Entry 1$)$. To probe the electronic effects of the co-catalyst on the reaction, we surveyed both electron-rich (Entry 2) as well as electron-deficient (Entry 3) thiophenols. Neither offered an 
improvement over thiophenol and 4-nitrothiophenol gave only moderate yields of the desired adduct (58\%). In our previous communication,[8a] we observed that phenyl disulfide could be employed in place of thiophenol as the co-catalyst for alkene hydroamination. We found that by replacing $20 \mathrm{~mol} \%$ thiophenol with $10 \mathrm{~mol} \%$ phenyl disulfide good yields could be maintained (Entry 7, 89\%). Diphenyl disulfide exists as an odorless solid and provides a practical advantage over thiophenol, which is a pungent and highly toxic liquid. Importantly, no reaction was observed in the absence of a co-catalyst (Entry 5). The inclusion of $25 \mathrm{~mol} \%$ 2,6-lutidine resulted in slightly higher product yields and cleaner crude reaction mixtures. Attempts to use $\mathrm{BocNH}_{2}$ in place of $\mathrm{TfNH}_{2}$ were unfortunately unsuccessful (Entry 9), as was the use of other sulfonamides (Ts, Ns; Entries 10-11).

We then began exploring the scope of the reaction with various $\beta$-methyl substituted styrenes as the alkene partner. Electron-rich methoxy-substituted styrenes gave the desired products in moderate to good yields (Table 1, entries 1-3). These substrates demonstrated the fastest times to completion, likely due to ease of their oxidation. Slightly less electron rich methyl-substituted styrenes were obtained in uniformly good yields, with variation of the substitution pattern having little effect (entries 4-6). Halogenated styrenes also provided the corresponding phenethylamine derivatives in good yields (entries 7-9). We obtained a lower yield for 4-tert-butyl substituted styrene, observing many oligomeric side products in the crude reaction mixture (entry 10). Styrenes with bulky arenes were also participants in the reaction, with 2,4,6- $\mathrm{Me}_{3} \mathrm{C}_{6} \mathrm{H}_{4}$ undergoing hydroamination in good yield (entry 11). We were able to extend the reaction to include bicyclic styrenes, as naphthalene and isosafrole gave the desired product in modest yields (entries $12 \& 13$ ). Heteroaromatic substitution was also tolerated, as demonstrated by the thiophene substituted product, albeit in low yield and with long reaction times (entry 14). All substrates gave complete anti-Markovnikov regioselectivity.

We then turned our attention to styrenyl substrates bearing different functional groups at the $\beta$-position (Figure 2). We were pleased to find that the reaction proceeded in good yields with esters, alcohols, and phthalimide protected amines as substituents on the styrenes (Entries 1-3). In particular, the use of allylic amines and alcohols provided 1,2-diamine and amino alcohol products, respectively (Entries $2 \& 3$ ). The chemoselectivity in Entry 3 should be underscored, as it is the only example, to our knowledge, of an alkene bearing a free alcohol in a hydroamination reaction. Perhaps most impressively, trisubstituted aliphatic cyclic alkenes underwent hydroamination with complete regioselectivity, despite having oxidation potentials in the vicinity of $+2.0 \mathrm{~V}$ vs. SCE (Entries $5 \& 6$ ). Due to its volatility, 3.0 equivalents of 2-methyl-2-butene were employed in the reaction.

In accord with our previous work in this area, we propose that the mechanism of this transformation begins with excitation of the mesityl acridinium catalyst (1) by $450 \mathrm{~nm}$ light, followed by single electron oxidation of the alkene by $1 *$ (Scheme 1 ). Reversible addition of triflylamide to the less-substituted position of $\mathbf{2}$ results in the formation of stable tertiary radical $\mathbf{3}$, which reacts with a hydrogen atom donor, presumably thiophenol, to furnish the final adduct (4). How thiophenol is generated is less clear. One potential mechanism involves homolysis of the $S$-S bond, either directly by light, or by energy transfer from 1*, 
giving rise to thiyl radical $\mathbf{5}$. This oxidizing radical could reset the acridinium catalyst via oxidation of the long-lived acridine radical 6. This seems feasible given the thiyl radical/ thiophenoxide redox couple $\left(E_{\mathrm{p} / 2}=+0.16 \mathrm{~V}\right.$ vs. SCE)[9] and the acridinium redox potential $\left(E^{\text {ox }}{ }_{1 / 2}=-0.49 \mathrm{~V}\right.$ vs. SCE),[10] ensuring that the redox event would be exergonic by nearly $15 \mathrm{kcal} / \mathrm{mol}$. Subsequent protonation generates the putative hydrogen atom transfer reagent, thiophenol. In previous control experiments, if thiophenol was employed as the co-catalyst, varying quantities of phenyl disulfide were observed in the crude reaction mixture, implicating the disulfide/thiophenol equilibrium.

Finally, we were able to employ heterocyclic amines as nucleophiles in this setting, providing access to potentially valuable nitrogen heterocycles (Figure 3).[11] We observed good reactivity between methoxy-substituted styrenes and pyrazole, indazole and 1,2,3triazole. Indazole gave a single $N 2$-regioisomer of product, congruent with prior observations of indazole alkylation selectivity under non-basic conditions (Entry 2).[12] The addition of poorly soluble imidazole gave a slightly lower yield and attempts to improve its solubility with various solvent combinations were unsuccessful (50\% yield, Entry 3). 1,1Disubstituted styrenes did not react productively with triflylamide but were reactive toward 1,2,3-triazole (Entries $5 \& 6$ ). For 1,2,3-triazole, substitution at the N1-position was the major regioisomer as expected due to the statistical advantage and increased electron density of N1/N3 over N2.[13] This reaction class should be of potential interest to the biomedical community as tool for lead drug candidate discovery.

In conclusion, we have demonstrated an anti-Markovnikov intermolecular hydroamination reaction of alkenes and amines employing a novel organic photoredox catalyst system. The broad reaction scope extends to trisubstituted aliphatic alkenes and $\alpha$ - and $\beta$-substituted styrenes with a variety of functional groups such as halides, esters, alcohols and protected amines. The amine coupling partner can be triflamide or heterocyclic amines. Though extended reaction times are required, this method expands the limited arena of antiMarkovnikov hydroamination for the direct addition of sulfonamides to alkenes. We are actively probing the mechanism of this and associated transformations as to the exact nature of the redox cycle and involvement of phenyl disulfide in the reaction mechanism.

\section{Experimental Section}

To a flame-dried 2 dram vial was added a magnetic stir bar, $N$-Me-mesityl acridinium catalyst $(1,1.0 \mathrm{~mol} \%)$, phenyldisulfide (10 mol \%) and the amine (1.5 equiv). The reaction vessel was purged with nitrogen, then 2,6-lutidine ( $25 \mathrm{~mol} \%)$, the alkene (1.0 equiv) and dichloromethane (sparged for $15 \mathrm{~min},[0.5 \mathrm{M}]$ ) was added. The vial was sealed with Teflon tape and irradiated with a blue LED lamp $(450 \mathrm{~nm})$ at room temperature. Reactions were quenched with a solution of TEMPO $(\sim 5 \mathrm{mg})$ in dichloromethane $(0.2 \mathrm{~mL})$ and concentrated in vacuo. The final products were purified by silica gel chromatography using the conditions given in the Supporting information.

\section{Supplementary Material}

Refer to Web version on PubMed Central for supplementary material. 


\section{Acknowledgments}

Supporting information for this article is available on the WWW under http://www.angewandte.org or from the author.

The project described was supported by Award No. R01, GM098340 from the National Institute of General Medical, Sciences, UNC-CH and an Eli Lilly New Faculty Award. We also are grateful to Dr. Mark Scott for insightful discussions.

\section{References}

[1]. O’Hagan D. Nat. Prod. Rep. 2000; 17:435-446. [PubMed: 11072891]

[2]. Müller TE, Hultzsch KC, Yus M, Foubelo F, Tada M. Chem. Rev. 2008; 108:3795-3892. [PubMed: 18729420]

[3]. For examples of intermolecular anti-Markovnikov hydroaminations using strong bases, see: Kumar K, Michalik D, Castro IG, Tillack A, Zapf A, Arlt M, Heinrich T, Böttcher H, Beller M. Chem. Eur. J. 2004; 10:746-757. [PubMed: 14767940] Horrillo-Martínez P, Hultzsch KC, Gil A, Branchadell V. Eur. J. Org. Chem. 2007:3311-3325. Zhang X, Emge TJ, Hultzsch KC. Angew. Chem., Int. Ed. 2012; 51:394-398.

[4]. For examples of intermolecular anti-Markovnikov hydroaminations using late transition metal or lanthanide catalysts, see: Beller M, Trauthwein H, Eichberger M, Breindl C, Herwig J, Müller TE, Thiel OR. Chem. Eur. J. 1999; 5:1306-1319. Utsunomiya M, Kuwano R, Kawatsura M, Hartwig JF. J. Am. Chem. Soc. 2003; 125:5608-5609. [PubMed: 12733880] Ryu J-S, Li GY, Marks TJ. J. Am. Chem. Soc. 2003; 125:12584-12605. [PubMed: 14531704] Utsunomiya M, Hartwig JF. J. Am. Chem. Soc. 2004; 126:2702-2703. [PubMed: 14995178] Takaya J, Hartwig JF. J. Am. Chem. Soc. 2005; 127:5756-5757. [PubMed: 15839651] Munro-Leighton C, Delp SA, Alsop NM, Blue ED, Gunnoe TB. Chem. Commun. 2008:111-113. Zhu S, Niljianskul N, Buchwald SL. J. Am. Chem. Soc. 2013; 135:15746-15749. [PubMed: 24106781] Barrett AGM, Brinkmann C, Crimmin MR, Hill MS, Hunt P, Procopiou PA. J. Am. Chem. Soc. 2009; 131:12906-12907. [PubMed: 19705841] Brinkmann C, Barrett AGM, Hill MS, Procopiou PA. J. Am. Chem. Soc. 2012; 134:2193-2207. [PubMed: 22239542]

[5]. For a radical-based approach, see: Guin J, Mück-Lichtenfeld C, Grimme S, Studer A. J. Am. Chem. Soc. 2007; 129:4498-4503. [PubMed: 17371026]

[6]. Yamashita and Masuda demonstrated the intermolecular anti-Markovnikov hydroamination with stoichiometric quantities of UV-activated photooxidants: Yamashita T, Shiomori K, Yasuda M, Shima K. Bull. Chem. Soc. Jpn. 1991; 64:366-374. Yamashita T, Yasuda M, Isami T, Nakano S, Tanabe K, Shima K. Tetrahedron Lett. 1993; 34:5131-5134. Yamashita T, Yasuda M, Isami T, Tanabe K, Shima K. Tetrahedron. 1994; 50:9275-9286. Yasuda M, Kojima R, Tsutsui H, Utsunomiya D, Ishii K, Jinnouchi K, Shiragami T, Yamashita T. J. Org. Chem. 2003; 68:76187624. [PubMed: 14510533]

[7]. For recent examples of formal intermolecular anti-Markovnikov alkene hydroamination, see: Rucker R, Whittaker AM, Dang H, Lalic G. J. Am. Chem. Soc. 2012; 134:6571-6574. [PubMed: 22469028] Bronner SM, Grubbs RH. Chem. Sci. 2014; 5:101-106.

[8]. Nguyen TM, Nicewicz DA. J. Am. Chem. Soc. 2013; 135:9588-9591. [PubMed: 23768239] For additional anti-Markovnikov transformations from our laboratory, see: Hamilton DS, Nicewicz DA. J. Am. Chem. Soc. 2012; 134:18577-18580. [PubMed: 23113557] Perkowski AJ, Nicewicz DA. J. Am. Chem. Soc. 2013; 135:10334-10337. [PubMed: 23808532]

[9]. Larsen AG, Holm AH, Roberson M, Daasbjerg K. J. Am. Chem. Soc. 2001; 123:1723-1729. [PubMed: 11456773]

[10]. Fukuzumi S, Kotani H, Ohkubo K, Ogo S, Tkachenko NV, Lemmetyinen H. J. Am. Chem. Soc. 2004; 126:1600-1601. [PubMed: 14871068]

[11]. a) Wamhoff, H. Comprehensive Heterocyclic Chemistry. Katritzky, AR.; Rees, CW., editors. Vol. 5. Pergamon, Oxford: 1984. p. 669-732.b) Dehne, H. Methoden der Organischen Chemie. Schumann, E., editor. Vol. E8d. Thieme; Stuttgart: 1994. p. 305-320.c) Kolb HC, Sharpless KB. Drug Discovery Today. 2003; 8:1128. [PubMed: 14678739] 
[12]. a) Cheung M, Boloor A, Stafford JA. J. Org. Chem. 2003; 68:4093-4095. [PubMed: 12737599]

b) Luo G, Chen L, Dubowchik G. J. Org. Chem. 2006; 71:5392-5395. [PubMed: 16808535]

[13]. Senanayake CH, Krishnamurthy D, Haddad N, Lee H, Zhang L, Wang X-J. Org. Lett. 2009; 11:5026-5028. [PubMed: 19813750] 

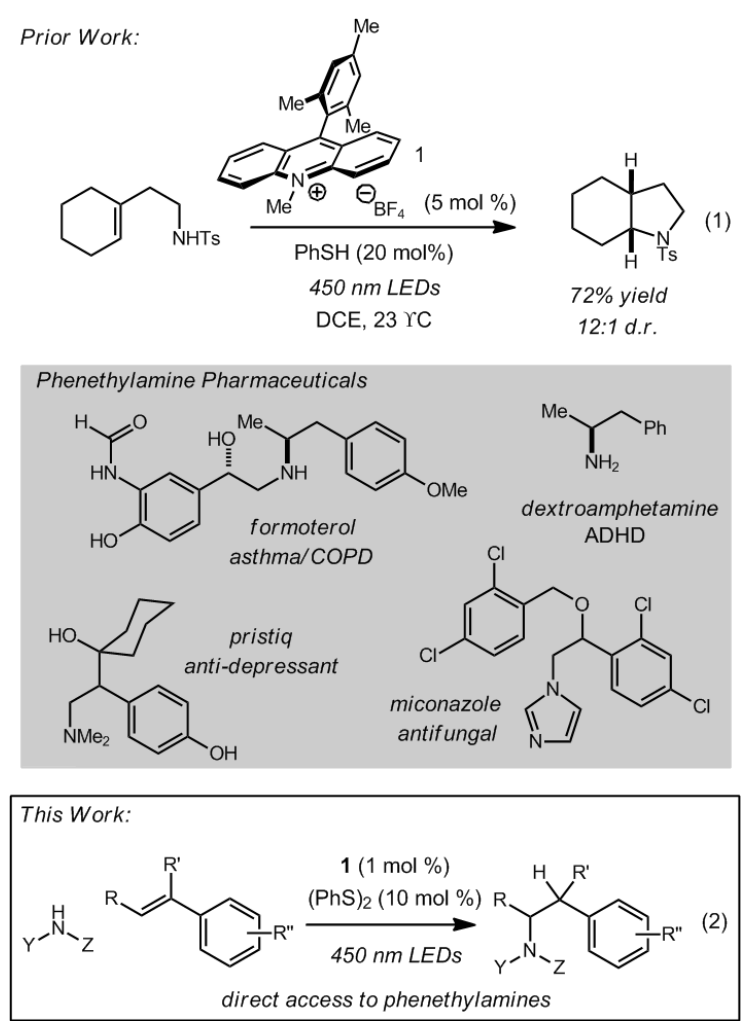

Figure 1.

Photoredox Strategy to Access Phenethylamines 


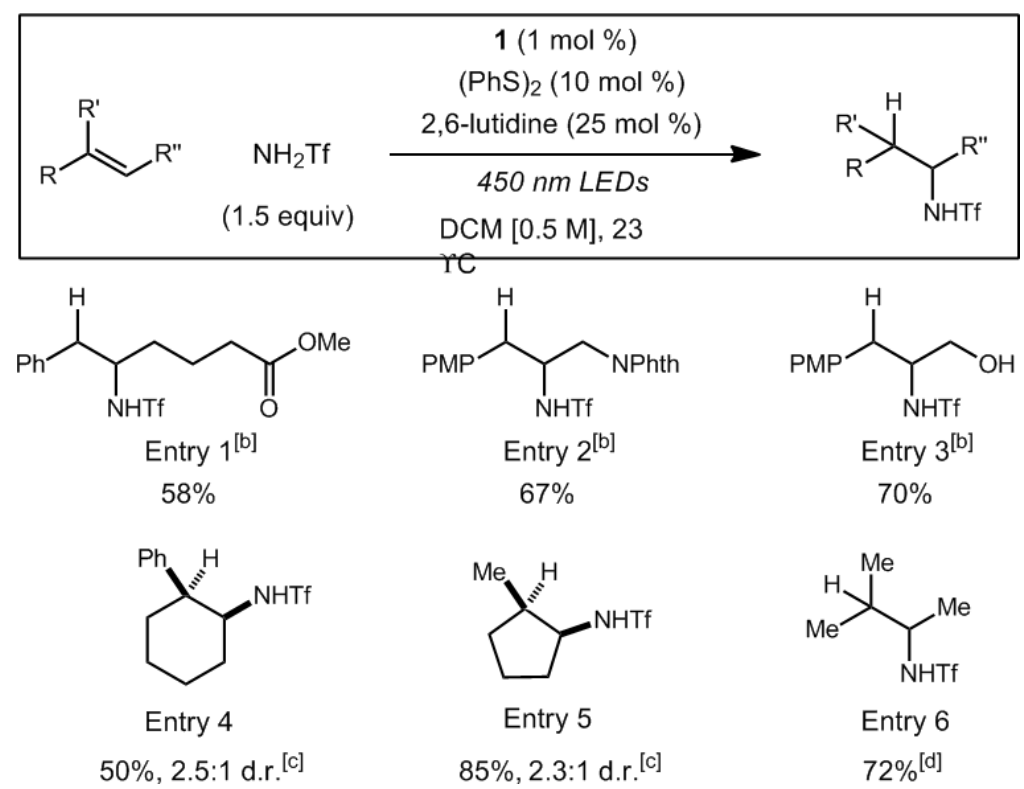

Figure 2.

Scope of the Intermolecular Anti-Markovnikov Hydroamination Reactions with Alkenes ${ }^{[a]}$ [a] All reactions irradiated with a $15 \mathrm{~W} 450 \mathrm{~nm}$ LED flood lamp. All reported as isolated yields, average of two trials. $\mathrm{Tf}=$ trifluoromethanesulfonyl; $\mathrm{PMP}=4-\mathrm{OMeC}_{6} \mathrm{H}_{4}[\mathrm{~b}] E-$ styrenes employed in reaction. [c] Diastereoselectivity determined by ${ }^{1} \mathrm{H}$ NMR of crude reaction. [d] 3.0 equiv alkene used. 


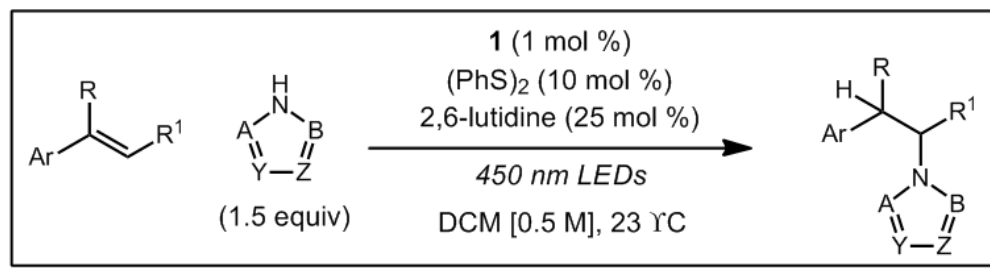<smiles>COc1ccccc1C(C)C(C)n1cccn1</smiles>

Entry 1

$83 \%$<smiles>COc1ccc(C(C)C(C)n2ccnn2)cc1</smiles>

Entry 4

$80 \%$

2:1 (N1:N2)<smiles>COc1ccccc1C(C)C(C)n1cc2ccccc2n1</smiles>

$57 \%$<smiles>c1ccc(C(Cn2ccnn2)(c2ccccc2)c2ccccc2)cc1</smiles>

Entry 5

$81 \%$

4:1 (N1:N2)<smiles>COc1ccc(C(C)C(C)n2ccnc2)cc1</smiles>

Entry $3^{[b]}$

$50 \%$

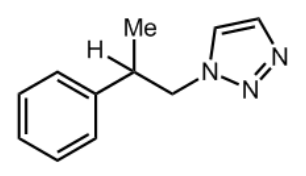

Entry 6

$41 \%$

$1.9: 1(N 1: N 2)$

Figure 3.

Scope of the Intermolecular Anti-Markovnikov Hydroamination Reactions with Heterocyclic Amines ${ }^{[a]}$ [a] All reactions irradiated with a 15W $450 \mathrm{~nm}$ LED flood lamp. Reported as isolated yields, average of two trials. Parenthesis indicate ratio of $N 1$ substitution: $N 2$ substitution. [b] 3.0 equivalents imidazole used. 


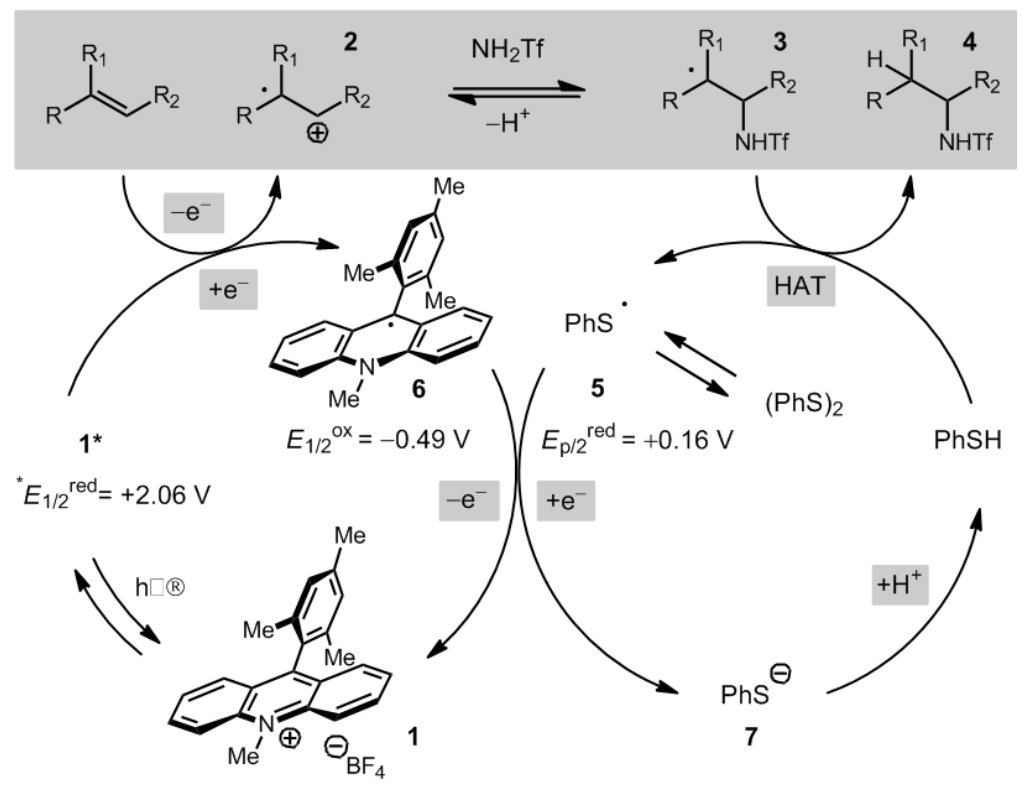

Scheme 1.

Proposed Mechanism for the Intermolecular Anti-Markovnikov Alkene Hydroamination Reaction. HAT = hydrogen atom transfer. 


\section{Table 1}

Optimization of the Anti-Markovnikov Alkene Hydroamination Reaction ${ }^{[a]}$

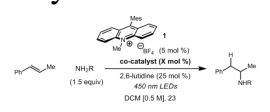

\begin{tabular}{ccccc}
\hline Entry & R & co-catalyst & mol \% & Yield \\
\hline 1 & Tf & thiophenol & $20 \%$ & $87 \%$ \\
2 & Tf & 2,6-dimethylthiophenol & $20 \%$ & $80 \%$ \\
3 & Tf & 4-nitrothiophenol & $20 \%$ & $58 \%$ \\
4 & Tf & phenyl disulfide & $20 \%$ & $78 \%$ \\
5 & Tf & no co-catalyst & $0 \%$ & $<5 \%$ \\
6 & Tf & phenyl disulfide & $5 \%$ & $35 \%$ \\
7 & Tf & phenyl disulfide & $\mathbf{1 0 \%}$ & $\mathbf{8 9 \%}$ \\
8 & Tf & phenyl disulfide & $100 \%$ & $40 \%$ \\
9 & Boc & phenyl disulfide & $10 \%$ & $8 \%$ \\
10 & Ts & phenyl disulfide & $10 \%$ & $<5 \%$ \\
11 & Ns & phenyl disulfide & $10 \%$ & $<5 \%$ \\
\hline
\end{tabular}

${ }^{[a]}$ All reactions irradiated with a $15 \mathrm{~W} 450 \mathrm{~nm}$ LED flood lamp and run on a $0.2 \mathrm{mmol}$ scale. Reported as ${ }^{1} \mathrm{H} \mathrm{NMR}$ yields vs. [( $\left.\mathrm{H}_{3} \mathrm{C}\right)_{3} \mathrm{Si}_{2} \mathrm{O}$ internal standard. $\mathrm{Tf}$ = trifluoromethanesulfonyl; Boc = ferf-butoxycarbonyl; $\mathrm{Ts}$ = 4-methylbenzenesulfonyl; Ns = 4-nitrobenzenesulfonyl. 
Table 2

Scope of the Intermolecular Anti-Markovnikov Hydroamination Reactions with Styrenyl Substrates ${ }^{[a]}$

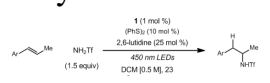

\begin{tabular}{|c|c|c|c|}
\hline Entry & Ar & Time & Yield $^{[b]}$ \\
\hline 1 & $2-\mathrm{OMeC}_{6} \mathrm{H}_{4}$ & $48 \mathrm{~h}$ & $55 \%$ \\
\hline 2 & $3-\mathrm{OMeC}_{6} \mathrm{H}_{4}$ & $48 \mathrm{~h}$ & $69 \%$ \\
\hline 3 & 4- $\mathrm{OMeC}_{6} \mathrm{H}_{4}$ & $48 \mathrm{~h}$ & $73 \%$ \\
\hline 4 & 2- $\mathrm{MeC}_{6} \mathrm{H}_{4}$ & $72 \mathrm{~h}$ & $76 \%$ \\
\hline 5 & $3-\mathrm{MeC}_{6} \mathrm{H}_{4}$ & $72 \mathrm{~h}$ & $73 \%$ \\
\hline 6 & 4- $\mathrm{MeC}_{6} \mathrm{H}_{4}$ & $72 \mathrm{~h}$ & $84 \%$ \\
\hline 7 & $\mathrm{Ph}$ & $72 \mathrm{~h}$ & $72 \%$ \\
\hline 8 & 4- $\mathrm{FC}_{6} \mathrm{H}_{4}$ & $96 \mathrm{~h}$ & $77 \%$ \\
\hline 9 & 4- $\mathrm{ClC}_{6} \mathrm{H}_{4}$ & $72 \mathrm{~h}$ & $75 \%$ \\
\hline 10 & $4-t-\mathrm{BuC}_{6} \mathrm{H}_{4}$ & $72 \mathrm{~h}$ & $43 \%$ \\
\hline 11 & $2,4,6-\mathrm{Me}_{3} \mathrm{C}_{6} \mathrm{H}_{2}$ & $72 \mathrm{~h}$ & $64 \%$ \\
\hline 12 & 2-naphthyl & $72 \mathrm{~h}$ & $63 \%$ \\
\hline 13 & & $96 \mathrm{~h}$ & $57 \%$ \\
\hline 14 & & $144 \mathrm{~h}$ & $35 \%$ \\
\hline
\end{tabular}

${ }^{[a]}$ All reactions irradiated with a 15W $450 \mathrm{~nm}$ LED flood lamp.

${ }^{[b]}$ Isolated yields, average of two trials. $\mathrm{Tf}=$ trifluoromethanesulfonyl. 